\title{
PLANEJAMENTO DE CUIDADOS DE ENFERMAGEM EM UNIDADE DE TERAPIA INTENSIVA
}

\author{
Alice Martins Gomes * \\ Carmélia Oliveira **
}

I - Introdução: Em nossa experiência, observamos que o planejamento de cuidados de enfermagem em Unidade de Terapia Intensiva apresenta características próprias. Baseia-se o desenvolvimento das atividades de enfermagem em situações vigentes e, quase sempre, de emergência. Deste modo, um levantamento de dados para elaboração de histórico de enfermagem torna-se pouco significativo, exige tempo e não atinge o objetivo do cuidado intensivo - atendimento do paciente em tempo útil por meio de recursos materiais e humanos concentrados.

Uma vez estabelecida a idéia de que as atividades de enfermagem são desenvolvidas de acordo com as necessidades apresentadas no momento pelo paciente, pensamos na elaboração de um impresso que propiciasse meios para o planejamento e registro sistematizado dos cuidados.

O impresso foi criado, considerando-se as características apresentadas pelos pacientes internados na Unidade de Terapia Intensiva, da Sociedade Beneficente de Senhoras - Hospital Sírio-Libanês, São Paulo.

A Unidade é geral, recebendo portadores de afecções diversas, que, em sua maioria, apresentam comprometimento de vias aéreas (primário ou secundário), alterações hemodinâmicas e metabólicas. (tabela I).

* Enfermeiras da Unidade de Terapia Intensiva do Hospital Sírio Libanês.

** Auxiliar de ensino do Departamento de Enfermagem Médico-Cirúrgica da Bscola de Enfermagem da U.S.P. 
Tabela I - Distribuição de paciente admitidos na Unidade de Terapia Intensiva do Hospital Sirio-Libanês, durante o mês de junho de 1974, segundo tipo de afeç̧ão.

\section{Tipo de afeç̧ão}

\section{N.O de pacientes}

Respiratória

Gastrointestinal

Renal

Cardiovascular

Neurológica

Endócrina

Ortopédicas
19

8

12

10

3

4

2

TOTAL

58

Fonte: Relatório mensal de atividades da Unidade de Terapia Intensiva do Hospital Sírio-Libanês, junho de 1974.

II - Caracteristicas da Unidade de Terapia Intensiva do Hospital Sirio-Libanês:

Número de leitos: 11.

Porcentagem de ocupação: $75 \%$

Regime de trabalho do serviço de enfermagem: 42 horas semanais. Horas cuidado: 17

Pessoal disponivel

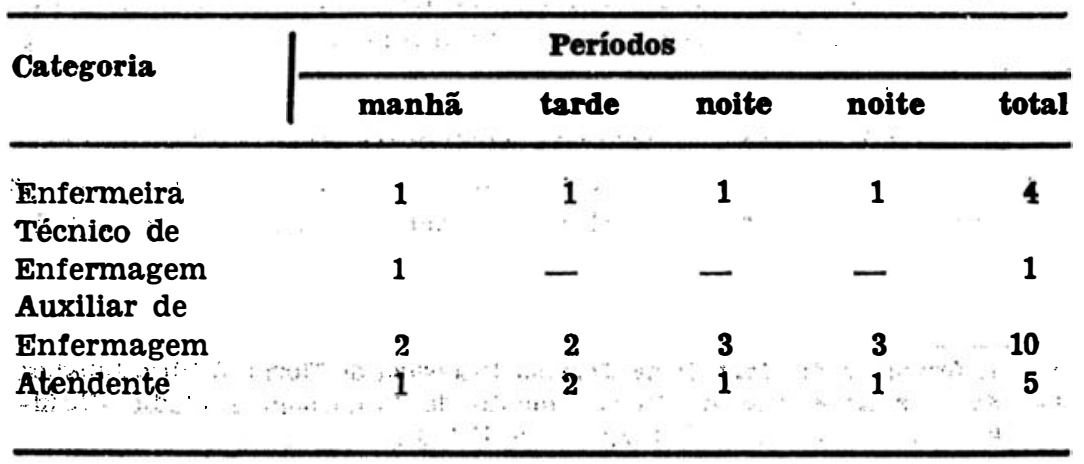


III - Objetivos do impresso:

1. Planejamento individualizado do cuidado do paciente;

2. Sistematização de cuidados de enfermagem, isto é, a combinação de dados e informações a respeito do atendimento total do paciente. Visa o melhor cuidado com o melhor rendimento do trabalho e poupança de tempo e movimento.

IV - Apresentação do Impresso: O plano apresentado no anexo I foi elaborado a partir do levantamento das necesisdades do paciente considerando-se que as mesmas estāo sujeitas. a variaçōes dentro de determinados periodos, isto é, que as condições do paciente de terapia intensiva apresentam alterações consideráveis num curto espaço de tempo.

O planejamento procura fornecer informações e dados que permitam uma avaliação das condições gerais do paciente, a orientação das condutas médicas e de enfermagem, a interaçãa entre os Serviços Médico e de Enfermagem.

Como o balanço em nossa unidade é fechado às 6 horas da manhã, o impresso apresenta como primeiro horário para planejamento 7 horas.

A assistência referente a sinais vitais, controle hídrico e cuidados especiais é apresentada em colunas e os horários nas linhas horizontais.

1. Sinais vitais: A primeira coluna destina-se ao registro da temperatura e a segunda ao registro de respiração. Logo após seguem-se colunas para os controles referentes à hemodinâmica, ou seja, pulso, pressão arterial e pressão venosa central. $O$ registro de algum outro parâmetro, não muito frequente em nossos pacientes, como por exemplo pressão arterial média ou frequência cardíaca poderão ser efetuados na coluna em branco.

2. Controle hídrico: Aqui é lançada a quantidade de líquidas ingeridos (por via oral, sonda gástrica e parenteral) e eliminados, (por meio de diurese e sonda gástrica). As colunas em branco são para outras infusões e eliminações.

3. Cuidados especiais: Acreditamos que a atenção da enfermagem em Unidade de Terapia Intensiva deve estar voltada para a preservação de órgãos vitais. Considerando que a manutenção de uma boa função pulmonar depende em grande parte da assistência de enfermagem, e que os auxiliares precisam ser estimulados a partici- 
par desta assistência, focalizamos com cuidados especiais, em primeiro lugar,. os relacionados às afecções respiratórias, na seguinte ordem:

1.․ - exercício respiratório: a ordem deste cuidado pode ser complementada com $o$ aparelho a ser utilizado e a duração do mesmo; 2. ${ }^{\circ}$ - tosse e respiração profunda: cuidado especial para pacientes ccm respiração espontânea, sem auxílio de respirador; ou quando está com respirador sem dispositivo próprio para variação do ar corrente;

3.๑ - aspiração traqueal: a técnica de aspiração traqueal por nós usada inclui a alternância de pressão do “cuff", com aspiração prévia da cavidade oro-faringea;

4. - higiene oral: este cuidado é apresentado em seguida ao da aspiração traqueal por fazer parte das vias aéreas superiores e, também, porque os pacientes estão acamados, dependentes e, na maioria das vezes, em jejum.

A seguir existem quatro colunas em branco para cuidados não comuns à maioria dos pacientes, como controle de hematócrito, tempo de coagulação, ou ainda, para um cuidado especial como o dos olhos, quando há excesso de secreção, e outros;

$5 .^{\circ}$ - glicossúria e cetonuria: são dados controlados com muita frequência em nossos pacientes; pela elevada faixa etária, por estarem na maioria das vezes, sujeitos a fatores desencadeantes de disfunção metabólica, como a cirurgia.

Em seguida existe uma coluna em branco para outro eventua! controle bioquímico.

6. - Movimentação: este cuidado pode ser complementado com orientações, por exemplo: movimentação ativo ou passiva de membros superiores ou inferiores. A finalidade destes cuidados é prevenir a atrofia muscular e trombose venosa;

7.0 - mudança de decúbito: sempre que seja possível, é necessár:a e obrigatória para mobilizar a secreção pulmonar e refazer a circulação em áreas sob pressão.

4. Observações de enfermagem: Reservamos este espaço para registrar as observações da enfermeira com relação a: nível de consciência, mudança no aspecto ou cor de secreções; exames especializados; alterações observadas na colaboração da pele ou escarrificações e, ainda, introdução ou retirada de sondas e catéteres. O espaço é pequeno, portanto, a anotação deve ser selecionada e bastante objetiva

5. Outros cuidados: Neste item fazemos os registros anotando os valores de peso e "checando" os demais dados, desde que rea.izados. 
Anotamos ainda, o material que for encaminhado para cultura, como secreções, catéteres, sangue, etc.

V - COMO PLANEJAR OS CUIDADOS - A enfermeira programa os cuidados a partir das informações recebidas na passagem de plantão, de um rápido exame físico do paciente e das necessidades identificadas no momento. Utiliza ainda, como meios de informação os dados registrados no periodo antecedente.

A programação é feita somente para o seu período de trabalho. isto é, seis horas. Convencionalmente assinala-se com um ponto a coluna do parâmetro a ser verificado (ou do cuidado a ser executado) e a linha correspondente aos horários em que o mesmo deve ser verificado (ou executado). Anexo I.

Todos os itens seguem a mesma orientação para planejamento, com exceção da infusão por via parenteral, para a qual é feita anotação do volume após cada unidade infundida, na coluna de soros.

Os cuidados executados são "checados" pela pessoa que atende - paciente.

VI - CONCLUSÃO: Elaborada a folha para planejamento de cuidados, colocamo-la em uso pela equipe de trabalho, durante um mês. Concluímos que ela:

1. ${ }^{\circ}$ propicia um planejamento sistemático de cuidados de enfermagem.

2..$^{\circ}$ proporciona meios para a interação de atividades médicas e de enfermagem.

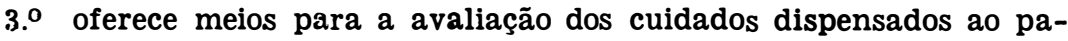
ciente e

4. ${ }^{\circ}$ atinge os objetivos da unidade.

VII - BIBLIOGRAFIA CONSULTADA

1 - BURREL, L.O. \& BURREL, Z.L. - Intensive Nursing Care. Saint Louis, Mosby, 1973.

2 - CLARKE, D.B. - Intensive care for nurses. Oxford and Edimburg, Blackwell Scientific Publications. 1971.

3 - LAMBERSTEN, E.C. - Equipe de Enfermagem Organização e Funcionamento. Trad. de Clarice Ferrarini. Associação Brasileira de Enfermagem, 1966.

4 - STORLIE, F. at al - Principles of Intensive Nursing Care. New York, Meredith Corporation, 1972. 


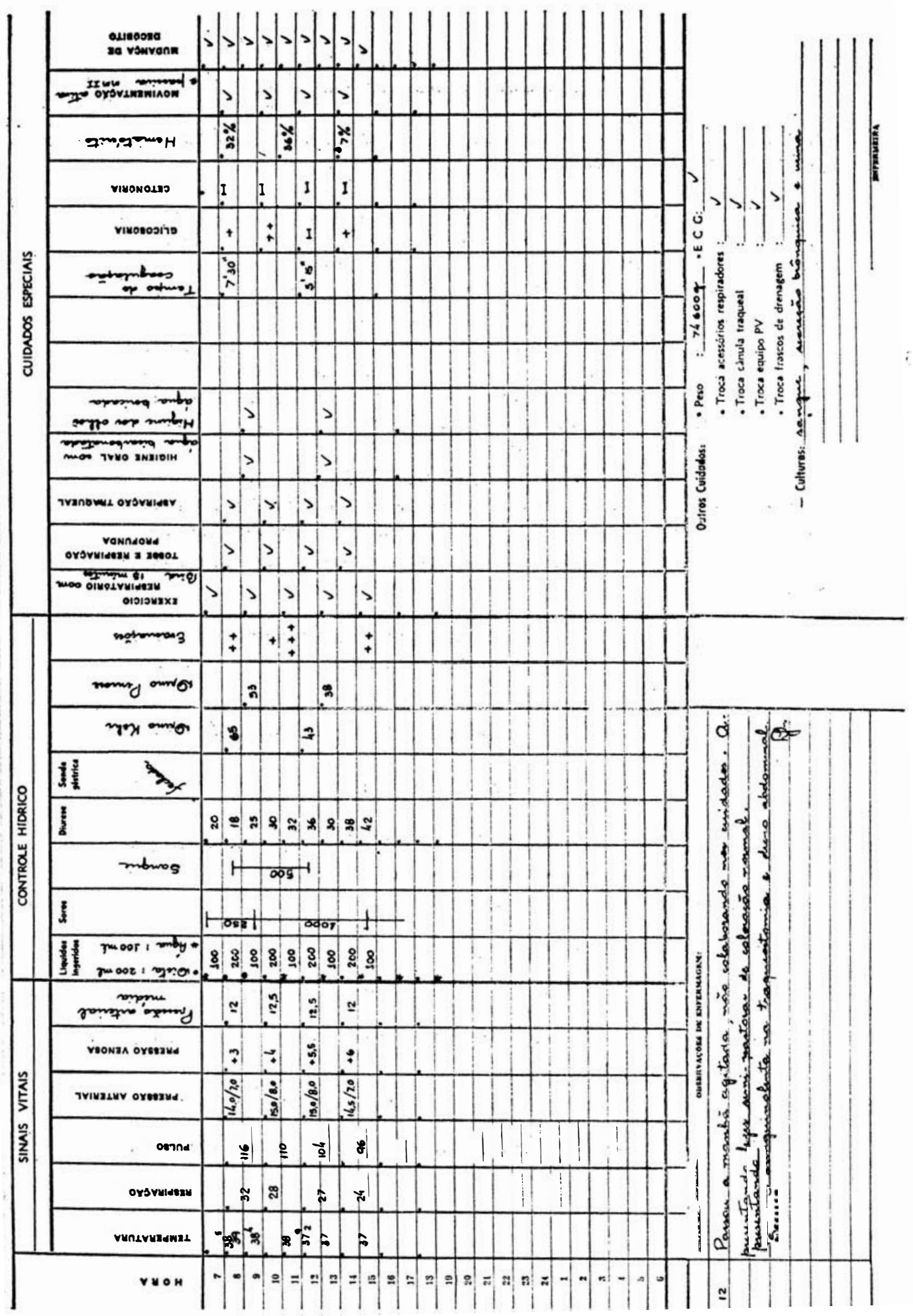

